Article

\title{
Migratory Realities: The Interplay of Landscapes in the Guyanese Emigrant's Reality in Jan Lowe Shinebourne's The Godmother and Other Stories
}

\author{
Abigail Persaud Cheddie \\ Faculty of Education \& Humanities, University of Guyana, Georgetown 413741, Guyana; \\ luannapersaud@yahoo.com; Tel.: +592-222-4923
}

Received: 29 November 2018; Accepted: 8 January 2019; Published: 12 January 2019

check for updates

\begin{abstract}
Guyana's high rate of migration has resulted in a sizeable Guyanese diaspora that continues to negotiate the connection with its homeland. Jan Lowe Shinebourne's The Godmother and Other Stories opens avenues of understanding the experiences of emigrated Guyanese through the lens of transnational migration. Four protagonists, one each from the stories "The Godmother," "Hopscotch," "London and New York" and "Rebirth" act as literary case studies in the mechanisms involved in a Guyanese transnational migrant's experience. Through a structuralist analysis, I show how the use of literary devices such as titles, layers and paradigms facilitate the presentation of the interplay of landscapes in the transnational migrant's experience. The significance of the story titles is briefly analysed. Then, how memories of the homeland are layered on the landscape of residence and how this interplay stabilises the migrant are examined. Thirdly, how ambivalence can set in after elements from the homeland come into physical contact with the migrant on the landscape of residence, thereby shifting the nostalgic paradigm into an unstable structure, is highlighted. Finally, it is observed that as a result of the paradigm shift, the migrant must then operate on a shifted interplay that can be confounding. Altogether, the text offers an opportunity to explore migratory realities in the Guyanese emigrant's experience.
\end{abstract}

Keywords: Guyanese diaspora; emigrant experiences; interplay of landscapes; Shinebourne

\section{Introduction}

'Culturally' located in the Caribbean, Guyana falls into a group of countries associated with a high rate of emigration. In the last 30 years alone, millions of residents have migrated in an upward trend from the 15 Caribbean Community (CARICOM) countries, Guyana included. The estimated number of emigrants increased from 1.5 million in the 1985 to 1990 interval to 3.25 million in the 2010 to 2015 interval (Gill et al. 2018, as cited in Danns, Griffith and Yaw, 2018, location 1004-1072). In 2013, Guyana ranked fifth on the list of Top Emigration Countries, with the top three destination countries being listed as the United States, Canada and the United Kingdom (World Bank Group 2016, pp. 4, 137). Fernandes (2018), writing for the Guyana Guardian, reported that there are "more than half a million" Guyanese emigrants abroad, "making Guyana one of the countries with the largest number of emigrant citizens abroad, per capita ... ." Meanwhile, the World Population Review (2018) approximates Guyana's current population as 784,013. Considering children born of Guyanese migrants, the reality might be that the number of Guyanese living at home and abroad is startlingly similar. Among the reasons for Guyanese emigration are " ... seeking livable incomes and a better way of life .... security reasons ... . disillusionment with the country's poor governance and its persistent underdevelopment" (Danns 2018 as cited in Danns, Griffith and Yaw, 2018, location 7703). However, even though such a large portion of the Caribbean and Guyana's population resides abroad, 
evidence of interest in home countries can be seen in remittances; for instance, an estimated 337 million U.S. dollars remitted to Guyana in 2015 has been reported (World Bank Group 2016, p. 137). More than this visibly quantifiable connection of remittances, however, is the upsurge in the need to understand the mechanisms that are involved in the migrant's negotiation of two or more places-their country of birth and their country of residence (and their country of origin or parents' origins). Current research in the Caribbean diaspora shows attempts at studying the mechanisms of belonging to two or three spaces at the same time via sociological (Smith 2018) and literary (Rahman 2018) lenses (as cited in Danns, Griffith and Yaw, 2018).

The navigation of the homeland space and the space of residence as presented in fiction by Guyanese writers in the diaspora is central to this paper. Ramdeholl (2018), describes the Guyanese experience of living in two spaces; she says that the "act of migrating is similar to a lover's discourse (initial enchantment followed by withdrawing/falling out of love with that place/space). The migrant dwells in this space of difference .... The migrant engages in a chameleon dance (apart yet part of ... )" (as cited in Danns, Griffith and Yaw, 2018, location 7526). More and more, Guyanese fiction in the diaspora has come to carefully present this complex 'lover's discourse,' this 'chameleon dance.' The narrator in Pauline Melville's short story "Eat Labba and Drink Creek Water" from her collection of short stories Shape-Shifter (Melville 1990), for instance, illustrates the Guyanese emigrant's balancing act between the Guyanese and British landscapes: "Once I dreamed I returned by walking in the manner of a high-wire artist, arms outstretched, across a frail spider's thread suspended sixty feet above the Atlantic attached to Big Ben at one end and St George's Cathedral, Demerara, at the other" (pp. 148-49). This terrifying image, in addition to the narrator saying that it took her 22 days to get across the wire in the dark night with only the light of the shining moon, emphasises a limbo landscape that is death-defying to manoeuver. In the same extract, the narrator asserts: "We do return and leave and return again, criss-crossing the Atlantic, but whichever side of the Atlantic we are on, the dream is always on the other side" (p. 149). Here, Melville captures how the migrant undergoes a process of balancing his place on two sides, each side propelling the motion to the other side, with no indication of the motion being brought to a halt.

Jan Lowe Shinebourne's The Godmother and Other Stories (Lowe Shinebourne 2013) provides an opportunity for a similar glimpse into the interplay of the two sides of the Atlantic in a Guyanese emigrant's experience. In several stories, she explores the function of memory in the interplay of landscapes, as the interplay constructs a limbo consciousness that seems necessary for the emigrant's survival. These stories suggest that what the migrant experiences is not a haphazard, useless fusion of two worlds, but rather an existence dependent on the organic, fluid interplay of the two landscapes. Ultimately, the fluidity of Lowe Shinebourne's overlaying presentation of images from two landscapes is striking. She ensures that her protagonists never struggle with the approach to memory, and that their psychological mobility between landscapes of origin and residence is organic and almost effortless. The overlaying of emotion and experience is natural, and the interplay becomes inevitable for the migrant, as the eponymous godmother says, "This memory is very easy to live. I slide into it so easily ... Sometimes, it is this easy to live in the past and present" (p. 75).

Admittedly, in three of her four novels-Timepiece (Lowe Shinebourne 2012), Chinese Women (Lowe Shinebourne 2010), and The Last Ship (Lowe Shinebourne 2015), the author gives space to her protagonists' emigration from Guyana; however, it is in The Godmother and Other Stories that she appears to have freed herself from the burden or responsibility of realistic historical representations of Guyana's past, and allows for an engagement in more fluid expressions of transnational experiences. Annie-Marie Lee-Loy (2008) confirms such expressions when she says that " ... in this collection, it is the characters themselves who are the focus of the stories, not their historical contexts .... [Shinebourne] also reveals an ability to evoke a poetic sensuality that has sometimes been lost in her more political novels ... " (p. 182). It is in this 'poetic sensuality' that Lowe Shinebourne manages to use landscapes to convey the emigrant's experience; “. .. Shinebourne's work not only challenges the boundaries of time and space, it also ultimately affirms the blurred spaces where they collide 
as vital locations from which to articulate identity" (Lee-Loy 2008, p. 180). The manner in which these 'collisions' and 'articulations' are presented forms the crux of the conveyance of the Guyanese emigrant's perspective in many of the stories.

\section{Theoretical Framework, Definitions and Objectives}

This fluid mental crossing of borders which Lowe Shinebourne explores through her protagonists in the stories can be situated amidst the framework of what Ozkul (2012) refers to as " ... transnationalism in migration studies" (1). In Glick Schiller et al. (1995) succinct definition, "Transnational Migration is the process by which immigrants forge and sustain simultaneous multi-stranded social relations that link together their societies of origin and settlement" (p. 48). For the purpose of this paper, these 'societies' will be referred to as landscape/s, in which all of the relevant topographical and other physical features and symbolic references to each society are included in the use of the term 'landscape'. The term 'landscape' is also referred to in this paper as a 'space,' thereby leaving room for more fluid conceptualisations of realities, as opposed to the more fixed geographical terms, 'location' or 'place'. Additionally, in order to situate this paper amidst a transnational framework, it is pertinent to note that there are reservations of transnationalism as a theory, as well as to the reality of its current somewhat undefined or evolving status (Ozkul 2012, p. 5); nevertheless, the main aim of transnational research is to show "... how persons involve themselves in relationships across different geographical places and borders, and how these relationships in turn change people's understandings of their location. In other words, transnational relationships change the ways in which people experience the place that they reside in and the boundaries of their nation-state" (Ozkul 2012, p. 7).

Current research focuses on terminologies and mechanisms such as 'spaces,' movements, fluidity, networking and transformations. More and more, the concepts of cultural assimilation and integration, which suggest a loss of some aspect of self from the country of origin, are challenged as the concept of migrants' dual existence gains ground (Giordano 2010). In four of the stories from Lowe Shinebourne's collection- "The Godmother," "Hopscotch," "London and New York" and "Rebirth," the protagonists are preoccupied with their consciousness of their country of birth, in addition to their awareness of their country of residence. In her historical summary of transnational research from the early 1990s, Ozkul observes that the general conclusion " ... underlined that migrants could be active in two distinct countries" (p. 2), a reality that each of Lowe Shinebourne's four protagonists experience. These protagonists - the eponymous godmother, Sylvia of "Hopscotch" and the women from "London and New York" and "Rebirth" also align with Ozkul's summary of research done by Levitt (2001), and Pries (2005) and Smith (2005), which concluded that " ... transnational networks were taking shape within fluid social spaces and were reproducing and creating 'the being' in two spaces simultaneously" (p. 2). Each of Lowe Shinebourne's four protagonists actively negotiate their two or more landscapes simultaneously.

Ozkul points out that, crucial to current transnational studies, is the need "to understand the mechanisms of transnational processes, as it is to understand their contributions to social science enquiry" (p. 7) and in her recommendations for further research in migrant transnationalism, she lists the need for interdisciplinary enquiry (p. 8). Hence, this paper is situated as a literary enquiry set against the backdrop of the social enquiry of the mechanisms of transnational migration. The main objective of this paper is to examine some of these mechanisms, as presented in Lowe Shinebourne's four selected short stories. In order to conduct a literary analysis of transnational processes, I will focus on Lowe Shinebourne's " .. . deftly crafted characters and her attention to structural details ... " (Lee-Loy 2008, p. 182), which are facilitated by her “ ... impressively pared down, minimalist style ...." (Creighton 2005). This minimalist style readily encourages a structuralist observation of how the emigrant characters operate through the workings of signifiers-such as the story titles, paradigms and layers. Through the use of such devices, Lowe Shinebourne opens avenues to consider how the 
emigrants' perceptions of their experiences of their two (or more) landscapes exist both independently, simultaneously and symbiotically.

In the introductory chapter to Identity and Migration in Europe, La Barbera (2015) outlines a process of relation that can apply to transnational migrants and for the purpose of this paper, can apply to Lowe Shinebourne's four protagonists as well:

Disillusionment and nostalgia contribute to idealising the country of origin, which is in turn beautified through memory. However, when the migrant returns home, the contrast between the ideal and the real reappears. To a certain extent, migrants live between idealization and disillusionment both in the receiving country and in the country of origin ... Their new condition is in between, at the borderland, in transit. The process that begins when one leaves his/her own country never ends, and it generates an unfinished condition of not yet belonging "here" but no longer "there". (p. 3)

I will therefore examine the presentation of the interplay of landscapes in Lowe Shinebourne's "The Godmother," "Hopscotch," "London and New York" and "Rebirth", using in a step-wise manner, La Barbera's outline above. To do this, firstly, I will briefly examine the significance of the story titles as an overview to the role of the fluidity of the motions between landscapes. Then, I will explore the positive effects of memory, and observe how Lowe Shinebourne uses the structure of layering to present 'beautified' memories of the homeland existing in a mental interplay with the landscape of residence. I will show how this interplay appears to be necessary for and stabilising to the migrant, regardless of the memories being positive or negative. Secondly, I will outline how ambivalence can set in after elements from the homeland appear in real time in the country of residence, and establish a kind of physical interplay that can then shift the idealistic and nostalgic paradigm experienced at step one above into a destabilising paradigm. Finally, I will highlight how the paradigm shift can become confounding and result in self-doubt or deep contemplation, ultimately producing a shifted interplay that constitutes 'an unfinished condition' that could affect future interplays in the migrant's experience.

\section{The Significance of Story Titles}

In the four stories examined from the collection, the protagonists all share the experience of surviving, sometimes ambivalently so, with the two layers of landscapes that are at interplay with each other. The godmother from the title story, and the character Sylvia from the story "Hopscotch", the I-narrator from "London and New York" and the often half-conscious protagonist of "Rebirth" make meaning out of their experiences only as the landscapes of origin and residence are layered upon each other. Immediately, the titles of the stories themselves signify the sense of the fluid conscious space evoked by the interplay of landscapes in the protagonists' experiences.

The title "The Godmother", for instance, suggests the telling of a migrant woman's experience as godmother on two landscapes. Through many mental re-visitations to Guyana, the 'long-lost' godmother manages to reorient herself as an active godmother on her landscape of residence. The title "Hopscotch" conveys a similar back-and-forth movement. The hopscotch image evokes a childish energetic momentum from box to box, which conveys the migrant's reality. It is a movement both free and limited, a movement guided by both control and chance, a contextual movement, a chronological movement and a game which, if by chance you cannot lay claim to a space in a box, creates a limbo experience until another opportunity appears. Up and down, back and forth, moving from this square to that, performing a balancing act on one leg, Sylvia hops from the memory of Guyana to the experience of England and back. Sometimes she flings herself from space to space-uninhibited, sometimes she is out of the game-confounded. Likewise, in "London and New York", the protagonist goes from the English landscape outdoors to the insides of The Canton, Omni, and Cafe Jam, restaurants that fluidly transport her into homeland experiences shared with her grandmother, father and mother. However, the story is titled "London and New York", not London and Georgetown (Guyana's capital), because her journeys to Chinatown and Brooklyn teach her about the 'criss-crossed' cultural footprints 
of her own existence- - of finding, for instance, Chinese cakes, not in Chinatown, New York as she found Chinese food in The Canton, London, but finding Chinese cakes Guyanese-style in a Guyanese restaurant located not in Chinatown, but in Brooklyn, New York. The migrant's experience takes the form of liquid motion, its identity defining itself through the placement and availability of foods as she moves through different cities. Finally, the title "Rebirth" is a play on being born again, with the identity of the homeland being allowed to freely exist in the country of residence. Through a near-death process that is excruciatingly painful, the protagonist pushes herself out from the womb constructed by the interplay of her past and present landscapes. In her rebirth, she chooses the stronger connections associated with her former identity, thereby making the interplay her new 'mother', and weaving, by choice, into her current 'English' existence, a gene pool of her past. "Rebirth" can be read as a painful and powerful metaphor of the emigrant's attempt at reconstruction of self, as can the other stories as well.

Each protagonist's experience is made possible through the interplay of the two main landscapes simultaneously at work in their lives. In each of the four selected stories, the use of one landscape in the Guyanese emigrant's experience devises meaning with the other.

\section{The Interplay of Local and Foreign Landscapes Stabilises the Guyanese Migrant}

In the four stories, the protagonists survive their migrant landscapes through what La Barbera refers to as 'beautified memories' of the homeland.

When "The Godmother" opens, the eponymous godmother confirms her location in England as she says, "Outside, the English rain is falling" (p. 73). Several layers then make an appearance. The migrant godmother's awareness of the English landscape around her is heightened; yet, throughout the story, superimposed on her physical reality of the "English rain" is the landscape of the past-Guyana, which re-introduces itself through memory. Superimposed on the rain of the godmother's landscape of residence firstly is the memory of the christening of her godchild that occurred many years ago in Guyana. Layered on top of this memory is the voice of Joseph, the godchild's father, travelling through the telephone to the protagonist, simultaneously in current time as well as in memory or past time. More intricately, layered on top of Joseph's current-time Canje (a place in Guyana) accent is the protagonist's own late father's voice, heard again through Joseph's Canje accent. The landscape layering process experienced by the migrant is complex.

The interplay is strengthened even more when the godmother finds that she cannot prepare for the arrival of the godchild-Yvette, and her parents, without evoking the manner in which her own mother prepared for visitors in the past. Unable to conduct the preparations without the evocation of memory, her mother's cleaning rituals for welcoming guests are enacted by the protagonist's own hands on the foreign landscape: "I dust the entire house: ceilings, walls, books, shelves, furniture, wash all the dust away with soap and water then rinse with perfumed water" (p. 74). Here old rituals are introduced to new spaces-the migrant space-and where necessary, adapted to the new space: "If we'd had carpets [in Guyana] they would have been shampooed, so I shampoo the carpets [in England]" (p. 74). So interfused are the two landscapes that in the otherwise cold kitchen in winter, the memory space of the perpetually hot Guyanese kitchen imposes itself on the current cold one, an interplay that strikes a balance and makes the godmother "happy" (p. 75). So interfused are memory and present time that the godmother cooking in current time merges into the memory figure of her mother from the past landscape: "I can see my mother dip a spoon into a karahi of boiling curry, trickle the gravy ... to the palm of her hand. I am in her kitchen again ... . I trickle metagee into my palm but taste from hers" (pp. 76-77). Furthermore, the godmother's journey to a Brixton shop to acquire some ingredients from her homeland is propelled by such buoyancy that she ignores the maps that she usually depends on, and she is carried along by an unusual floating holistic confidence in her mind and body, no doubt brought on by the empowering interplay of memories of home upon her current landscape (pp. 74-75). 
Undoubtedly, the godmother finds happiness and ecstasy in the seamless interplay of the two worlds separated by time and space. She becomes more confident and grounded through the process of cleaning the house, the dream-like purchasing of ingredients, the preparation of the meal and the opening of the door for her guests.

Similarly, in "Hopscotch," Sylvia cannot ever entirely leave Guyana behind, as her current experiences in her country of residence become laden with associations of the Guyanese landscape-where, for instance, something as simple as the sight of milk bottles on a doorstep in England turns into memories of ice-cream from home (p. 53). Like the godmother, Sylvia's memories from home function to stabilise and often justify her migrant status. Though her memories are not always pleasant, their interplay with her current landscape functions to remind her of her purpose in England, and makes her feel fulfilled, especially when she consciously allows the happier memories to roam freely in her mind. An example of her delight at the merging of the two spaces comes when she calls her friend Carmen through the operator: "The switchboard operator says 'Carmen' with her English voice. So comforting the sound of her name, even on English lips. It is the sound of two worlds coming together, an English voice pronouncing the name of an old friend from Guyana" (p. 57). Meeting with Carmen brings Sylvia to a deep sense of stability through memory: "There are few friendships like this to bring back my girlhood, to make me remember the taste of food I never eat anymore ... the feel of Guyana sun and rain and breeze ... walking barefoot on a hand-polished floorboard ... . She makes me feel as if I could be completely my same old self" (p. 59). Like the godmother, the happiness that Sylvia finds worth mentioning is associated with the interplay being at its sharpest, and memory being most 'beautified.'

Even though time marks its passage on her life on the English landscape, the effect of the interplay is still strongly retained almost two decades after Sylvia's migrant story begins. On meeting another friend Dell almost 20 years later from the date of the Guyanese ice-cream memories layered on the English milk bottles image, Sylvia is found to still be stabilising herself with a similar mental layering technique: "Love, hot buns and Caribbean tongue ... The memories are so strong now because Dell is making them strong. I have to remind myself we are in a cottage at the roadside of a solitary part of the English countryside. We are in England. I am living in the past" (p. 62). In Sylvia's mind, so fused are the two landscapes that she must constantly remind herself of her current location; she thinks: "Even the silence of an English village can resonate with Guyanese history" (p. 63). But though she steadily reminds herself of her physical location, it appears as if in order to achieve some stability, she must consciously scan the English landscape for its relationship with the landscape of her birth: "The thatch on the cottages here could just as well be thatch on a benab. Suffolk is flat like Guyana. In Devon, there is a small town ... [with] a seawall there, a real seawall that looks just like the Georgetown seawall. Even the beaches are similar. Sometimes, England can be like Guyana" (p. 60). Sylvia's intense desire to connect the two landscapes springs from her need to validate her existence in both places. Throughout the visit with her friend, Sylvia keeps nurturing and revelling in the interplay: "... Dell brings out plates of steaming hot prawn curry, and we lie on the ground at four, in the English afternoon, and eat the curry .... It was Dell and all the memories of our lives falling out of the big, blue summer sky that is like the Guyana sky" (pp. 60-61). In identifying the things that are simultaneously and seamlessly English and Guyanese, Sylvia finds stability. Through this interplay of memory and current reality, her world makes sense. As a migrant, she assures herself that her resident landscape can be just like her homeland, in order to convince herself that she has not really lost her original place in the world, a convincing that is crucial to her own ontology, and ultimately, to her survival as a migrant.

In "London and New York," the narrator finds stability through food in various consciously selected restaurants. In her migrant experience, and like the godmother and Sylvia, food from British Guiana, later Guyana, is superimposed on her everyday experiences. In The Canton, she manages to stay close to her Guyanese-Chinese grandmother's East Indian-influenced cooking, and this dining experience sustains her existence in England: "So while I sit at my table at The Canton, I am a secure 
child again in British Guiana .... When I eat roast Duck and Chinese greens at The Canton in London, I taste East Indian duck in their Chinese duck, I taste Guyanese calaloo in Chinese greens. In my memory, I am in a Guyanese garden" (p. 96). The protagonist also constantly seeks out a similar experience at Omni's, a restaurant closer to her residence, a restaurant that evokes memories of her father as he existed on another landscape. In fact, whenever the protagonist finds another restaurant that strengthens the interplay of the two landscapes, she appears more stabilised. This is the case when she discovers Cafe Jam in Brixton that fills her senses with dishes like her mother's African-Guyanese cooking: "When our meal arrived, it was cooked in the Guyanese style, down to the black cake dessert. Now I eat at Cafe Jam regularly and I am really happy when I have to wait a long time for the ingredients to be brought in from down the road" (p. 99). This narrator, like the godmother and Sylvia, revels in a deep-seated joy, as emphasised by her words 'really happy', as the interplay of landscapes impresses itself on her mind, and as the food keeps the channels of memory open and functions as a negotiator of her migrant identity.

Similarly, these channels of memory become fully open in "Rebirth." The migrant protagonist survives her excruciatingly painful experience of having three successive complicated surgeries by immersing herself in memories from her homeland. In her anaesthetised state in the theatre in England, she exists in a limbo space of two landscapes, and negotiates herself in a largely ambivalent but mostly positive way. Superimposed on her surgeries in the foreign hospital room, the protagonist retrieves memories of several figures, and cultural and religious influences from her past; they are: her mother, who emphasises the Britishness of the West Indies; the African woman called Miss K; the Christian Priest; the Hindu Indian Sadhu. The anaesthetised migrant swims between their ideologies that have combined and made up who she is. Furthermore, her own metaphorical death in the English hospital is superimposed on the physical deaths that occurred on the landscape of the past-the deaths of Miss $\mathrm{K}$, the protagonist's mother and grandmother and her uncle Darcus; through these associations of physical death, she is able to survive her own metaphorical death.

The water 'texture' of the story is accompanied by a swimmingly fluid mental narrative propelled by the water imagery used by the nurse: "She tells me the sun is hot. I am at home. She tells me I am in the Caribbean. She tells me I am swimming in the sea; it is warm and comforting and relaxing in the water; she tells me I am home" (p. 87). These 'beautified' images, invented by the nurse and imagined by the protagonist, contrast with the excruciating physical pain experienced in the hospital on a foreign land-the interplay allows the landscape of the homeland to overpower the current landscape, keeping the protagonist alive and forcing a psychological rebirth. Though the nurse's manufactured 'memory' here is ambivalent because it is the nurse creating her own version of Caribbean images that are generic to the tropics but not necessarily specific to the protagonist's country or the protagonist herself, it still helps the protagonist to survive. Altogether, like the first three protagonists, the sick woman manages to survive her death-like experience on the migrant landscape, through an interplay that stabilises her vital signs and that facilitates a re-birth of the migrant self that was forced to cope with all the difficult changes brought on by migration.

From the four cases above, it can be seen that superimpositions of the homeland on the current country of residence continue to dominate the migrant's experience, and fortunately so, since memory is strong and vivid, moving and grounding, stabilising. For each of the four migrant protagonists, memory, in particular, beautified and amplified memory is sustenance.

However, memory is also limiting, and though it is reliable and necessary for survival, it can startle and exclude, especially when the past meets the present, and the migrant's reality, 'stable' as it might have been, is re-constructed on the foreign landscape. Two worlds touching can create an ambivalent and sometimes destabilising current experience on the landscape of residence. 


\section{The Migrant's Ambivalent Experience of the Interplay Once the Past Appears in Current Reality}

The four migrant protagonists share similarly ambivalent experiences of the interplay of landscapes once the past physically confronts their current realities. La Barbera refers to the disillusionment that a return home can cause; however, neither of Lowe Shinebourne's protagonists literally return home, yet they still experience major disillusionment or they move into contemplative moods after experiencing some form of physical reference or contact from the homeland on the landscape of residence.

After her ecstatic preparation for her guests from Guyana, the godmother awaits eagerly for the "... past and the present [to] be joined" (p. 78). But for her, when these two worlds physically meet, they collide rather than flow seamlessly as they do in her mental re-migrations during the preparation of the meal. In the preparation, through memory, there is a unifying and empowering interplay; in the actual meal, there is a jolt of the spirit when the people she meets are different from who she remembers, and they fall flat in character in the flesh: "Certainly their faces hardly bear a resemblance to the faces in my memory" (p. 78). Further, the current image of Guyana presented over table-talk by Joseph appears ambivalent. Altogether, figures from the past meet the present, and the beautifully prepared meal appears to have disappeared from off the table in an irreverent and philistine manner. We don't hear much about the way in which the meal is shared and enjoyed with each other; rather, we hear of the end of the meal: "Finally, only the fruit salad and black cake remained-the last fragments of the dream meal" (p. 79). Nobody compliments the godmother on the meal, or seeks out a mutual exchange with her. No concern is shown for her experiences as a migrant, or for her feelings of nostalgia or her deep desire to re-establish a genuine human connection again with people from her homeland.

In fact, Joseph is only there for his own benefit. He spoils the dinner with his self-serving and pompous attitude, so much so that the godmother's ideal paradigm of hosting her "dream meal" for not only the guests from home, but in tribute of her past landscape and her very self, is shattered. By acting like a god, confiscating his daughter's gold earrings given to her by her godmother and demanding that the godmother present him with money, Joseph, with his materialistic approach, taints the empowering pure nostalgia that is experienced by the protagonist prior to the physical encounter with him. He succeeds in adding another layer of the old landscape in the protagonist's mind, this time in the shape of an unfulfilling and unpleasant encounter, challenging and who knows, perhaps even cancelling out the godmother's newfound optimism in her role. The happiness is drained out of her, and her anger at the participants, her disillusionment in the true ability of her homeland to stabilise her migrant life and uncertainty about her feelings about the relationship between the past and the present appear to flow into her current life. Her encounter with Joseph challenges the function of the 'beautified' memories, and affects the understanding of her role in her current location.

In the same way, when Sylvia meets her friends from home, their exchanges leave each other feeling betrayed, as is evident in the excerpt below from her conversation with her old friend Carmen:

"Don't call me English."

"The trouble with you is you forget what it is to be yourself. You are English now.

English, English, English."

"Carmen, if anything makes me forget how to be myself, how to be with you, it is what happened in Guyana ...."

"I have told you I will not listen to you criticising your country ... ."

“... You don't want me to speak ...." (p. 59)

The nostalgic texture of their friendship is confronted by the silent divide of migration that has threatened their relationship over the years. This confrontation transforms Sylvia's joy and connection into a paradigm of defensiveness and alienation. The same thread is taken up in Sylvia's conversation with her other best friend Dell: 
"Very funny, Dell. You going to give me a hard time too for living in London, like Carmen has done all these years? ..."

"... You could have stayed in the Caribbean. Why you had to go so far away?"

$\cdots$

$\ldots$

“... I have lived here with too much grief for England to impress me. I live with Guyana all

the time. I want to stop my memory, stop remembering, so I can start to live here." (p. 61)

It becomes clear that a migrant's reality is filled with irony. The very element of the migrant's sustainability-memory, becomes the debilitating force in daily personal growth. In these conversations, Sylvia, like the godmother, struggles with balancing the use of memory and warm bonds with persons from the landscape of the past, versus their current personalities, judgments and expectations of her. Carmen and Dell are figures from Sylvia's past and in her memory, they are unchanged. In their meeting, on some level, that healthy aspect of their friendship from the past does remain unchanged, but the circumstances of migration can affect persons' holistic relations. The disappointment comes as a result of the migrant assuming that because her memories are static and sustaining, that a physical interplay with figures from the past might possess the same outcome as the mental interplays. These mental interplays, however, are mostly controlled by the migrant's memories and imaginings, in comparison to the physical confrontations that are more so controlled by the other participants and other variables in current time. After the physical confrontations with Carmen and Dell, Sylvia's relationships with her closest friends are fiercely challenged, and everyone's feelings about her choice, or lack of choice, to migrate, remain tense and unresolved, despite the fact that they once shared a familial bond in Guyana.

Unlike, the godmother's and Sylvia's physical meetings with persons that they have actually known in the past, the protagonists of "London and New York" and "Re-birth" meet, instead, intermediaries who speak to them of their past, but who allow them, like the godmother's guests and Sylvia's friends, to experience a jolt of reflection.

The protagonist in "London and New York" in her attempt to find her mother's red bean cakes in Chinatown, New York, is reminded of her English and Caribbean accent by a stranger (p. 99). This encounter forces her to reflect on methods of survival in her migrant experience: "It reminded me how Caribbean people have developed the skills of cultural translation. We tune our ears to accents, learning to recognise and use them to map our everyday transactions. Without that skill and other ones, we would have no maps to negotiate with" (p. 99). Similarly, in her conversation on red bean cakes with the proprietor of a shop in Chinatown, the protagonist reminds herself of how she remains psychologically, culturally and socially situated, based on her landscape of birth. The exchange strongly highlights her daily existence as a migrant, and her continuous need to re-calibrate and validate her place in the world because she is a migrant. In the end, her encounters in Chinatown remind her of how some persons, like the Caribbean woman can understand her map, while others like the cake shop proprietor need to be educated about this map; she and the man " ... talked about the differences between the cakes [she] buy[s] in London's Soho and the cakes on display" (p. 100). In this exchange, the protagonist uses cakes to distinguish between a Chinese migrant to New York and herself: "We were translating to each other the specificities of our locations by talking about Chinese cakes. Cakes had become a metaphor of home to both of us" (p. 100). The protagonist's means of negotiating herself becomes affected as she realises that she must constantly renew her understanding of herself, both for herself and for others, as she journeys around the globe. For her, her own origins are easy to trace: she is a tourist in New York, who resides in England, who was born and raised in Guyana by fore-parents of Chinese, East Indian and African ancestry, with a Caribbean way of being that had been shaped by a fusion of their English colonial and combined ancestral pasts. In her mind, there are no contradictions or confusions in this complex identification of herself. For her, this distinguishability of her roots is crucial to her negotiation of self, and it must be explained and even defended to those who confront it through simplifications. Many migrants' sense of home and 
identity might be completely shaken if they lack the courage and opportunity to voice their story in the way that this protagonist is able to do successfully. Though she narrates her identity successfully, she still must face a world that maps her in terms of segments such as race, nationality, culture and her migrant status versus her more seamless understanding of herself. Her understanding of self is ideal, but when she is confronted by the 'real', in which she is not completely understood, she must rise to the challenge and bridge the gap before disillusionment can set in.

Unlike the narrator from "London and New York" who boldly engages in mental re-migrations home, and takes the time to articulate her identity to others, the protagonist in "Rebirth" appears to have repressed her story. Echoes and emotions of her homeland seem buried deep in her subconscious, and they swim to the surface to confront and save her only when she is heavily sedated. Though some of the memories that surface are unpleasant, she is not unhappy to exist in the interplay of landscapes. Yet, the mediation of the nurse and the Barbadian anaesthetist confound and disappoint her when she needs them to help her to fully mentally re-migrate. The nurse's purpose is to use the imagery of the Caribbean, ironically, to take her patient away from the imagined Caribbean, and to return her to full consciousness on the English landscape. However, the sedated migrant does not seem completely willing to consciously return to the English hospital room in a hurry, as she appears more self-aware of her history and identity in her half-conscious limbo state. The manufactured memory created by the care-giver is a kind nursing gesture and helpful in soothing the patient and keeping her conscious, but it is in the same vein, indicative of a colonial nurse with the "blue blue blue blue blue blue blue" (p. 87) eyes rearranging the migrant's power when she is at her physically weakest, and ironically, when she is most mentally capable of channelling her own authentic memories. The contact here, of a 'created' past made for the protagonist by a foreigner, is somewhat ambivalent and therefore as jarring as the experiences of the former three protagonists. Moreover, so is the interaction with the 'Caribbean' doctor; she says: "The anaesthetist is from Barbados so I tell him to go and call Miss $\mathrm{K}$ " (p. 83), but he replies patronisingly, not seriously: "All right darling, all right darling, I will go and get her, you just count to five and you will go to sleep and have real sweet dreams" (p. 83). Ambiguously, the strained echoes from home that reach her from these two caregivers are used to keep the protagonist pacified and alive, through what really feels to her like a 'dying' process. They do not really know what her mutterings and whispers mean. They dismiss her seemingly inarticulate, half-conscious homeland narrative with versions of their own-the nurse with a manufactured version and the anaesthetist with a dismissive version. Like the narrator of "London and New York", she must struggle for a means to re-calibrate and validate herself, even if she is half-conscious. Though her mental re-migrations leave the protagonist emotionally content, her contact with the intermediaries who bring echoes of home renders her extremely helpless in their presence in the hospital.

Evidently, elements of empowering nostalgic memory from the past can stabilise a Guyanese migrant, but when a subject from the past or an intermediary referencing the past landscape emerges on the current landscape of residence, the migrant can become startled if the experience challenges the stability that is provided by memory. When these physically confrontational experiences happen, they change the face of the initial interplay and shift the paradigm, thereby affecting future interplays for the migrant.

\section{Shifted Interplays}

Each of the four protagonists experiences a shifted interplay. This shift causes a new condition, a perpetual 'borderland' experience, as La Barbera calls it. After the experience of either disillusionment or defence, they all appear to be 'forever in transit,' perhaps until another cycle of 'beautified' memory comes along.

To begin with, there is a shifted interplay when the uncomfortable meeting with Joseph propels a paradigm shift in the godmother's approach to life. The story begins with her being happy and looking for ways to share herself but ends with her saying, "I clear away the remains of my dream dinner. I wash the plates, cooker, and walls and surfaces of the kitchen" (p. 80). The vigorous 
cleaning appears to be an attempt to erase the harsh meeting of the present with the past. The kitchen that was warmly infused earlier with memories and a dream meal suddenly becomes a place to be thoroughly cleansed. In the act of scrubbing, the godmother copes with her new ambivalent feelings towards people from home. Ultimately, she purges her current space to find some equilibrium, in order to determine how she will negotiate and manage the continuing interplay in her life thereafter. The ambiguous final sentence sets the mood for her resolution: "Yet, I am certain I detect a lingering scent of mothballs in the air" (p. 80). After all the scrubbing, the smell of the mothballs of the godmother's childhood-from her father's trunk in Guyana, a trunk from a different time and far-away place (pp. 75-76), is still superimposed in the English air. The interplay is still at work, but how the godmother relates to it has shifted by the end of the story. Her use of the words "detect," "lingering," "in the air" suggest a kind of permanently yoked, yet distanced and now permanently or temporarily detached relationship with her homeland.

Sylvia's experience is similar. At the end of the story, she emerges in an ambiguous space:

"Sylvia, Sylvia, wake up."

"I was dreaming." (p. 66)

In this dream space of 'memory dreams', she evaluates the falling away of hope and the use of façades: "No garden for us, just the sin of losing faith and you must hide it so well even you cannot find it, until the circle ends so that it festers away in darkness until it matures into a ripe evil" (p. 66). In comparison to the light-hearted opening scene of ice-cream and childhood play, the closing dream is dark and hopeless and terrifying, in which the subject is saved only by adapting a persona of pretence. Here, Sylvia seems to be referencing the lost faith of the migrant and the persona that she must adapt in order to live a migrant's life. When she wakes up, there is no real resolution, as there is none for the godmother; she wakes up, but the narrative still feels dream-like. Ultimately, Sylvia remains alienated from her friends and homeland. Her desires to forge connections are met with brick walls, not bridges. Her labels as deserter and traitor appear to permanently lock her out from her psychic home-an experience that is terrifying and disheartening. By the end of the story, the interplay is still operating through a dream medium, but Sylvia's relationship with it is more sober.

For the third protagonist, though individually she gains confidence and returns home with a bag of vegetables and is quite pleased with her progress, she still ends by narrating the criss-crossings that are permanently at play in the Guyanese migrant's experience, a state that she must continue to explore, interrogate and articulate, no matter how many years have passed from the first instance of migration. She says: "Later that night, I found red bean cakes, exactly like my mother's, in a Guyanese restaurant in Brooklyn. In London I get red bean cakes in Chinatown but not in Guyanese restaurants. In New York I do not find them in Chinatown but in a Guyanese restaurant in Brooklyn" (p. 101). The migrant now operates on a new paradigm, clearly articulating her discovered differences. She discovers that there is a place for everything, but the place is not the same in every context. The place changes, depending on how a person or a thing is socially read. A Guyanese migrant seems to have to keep re-reading herself, depending on the discovered contexts. The interplay forces the migrant from being happily content into a continuously contemplative mode with regard to her true place in the world.

Finally, the fourth migrant protagonist successfully experiences a re-birth; her way of viewing herself has shifted: "The ritual of washing goes on for a very long time. It is the earliest memory I have of myself now, now that I am born again" (p. 92). This is a wholly positive note. Yet the reader cannot help but wonder how functional is this re-birth on her landscape of residence. After she returns home from hospital, we do not know what her relationship with her husband will be. It is possible that she will have to psychologically separate from him in order to continue her existence with the new paradigm, especially since it does not appear as if he will be a part of her new framework, as she regards his visits to her in the light of a 'cultural' enemy: "Your husband has gone home, they said. Husbands are supposed to stay with their dead. You do not leave the dead on their own. You are supposed to sit up with the dead one night and one day" (pp. 83-84). The husband then does not 
understand the recesses of her heart, and so they have a culturally dysfunctional marriage. She will have to find ways to reconcile her homeland-associated re-birth with her foreign marriage, from which traces of her homeland appear to have previously been erased, in order to make the marriage generally functional. The reader has to assume that the patient's re-integration into society will not be simple or smooth. In her redeeming paradigm shift of empowering homeland images, the migrant protagonist might have become alienated from her marriage and her country of residence.

Notably, and depressingly so, all of the stories end in a limbo state with no definitive projections of their migrant futures. It is unclear what paths will be taken after the godmother is done scrubbing the kitchen, and when Sylvia wakes up from her dream, and when the protagonist from "London and New York" constantly re-evaluates her identity and when the anaesthesia fully wears off of the narrator of "Re-birth." The experience of landscape interplay results in a paradigm shift from contentment and happiness to disillusionment, alienation, sobering contemplation and uncertainty, respectively, for the protagonists.

\section{Conclusions}

Lowe Shinebourne's The Godmother and Other Stories provides an opportunity for entering into the Guyanese emigrant's experience, through the interplay of landscapes as experienced by the protagonists in "The Godmother," "Hopscotch," "London and New York" and "Rebirth." Her four selected protagonists act as literary case studies in the mechanisms involved in a transnational migrant's experience. Each protagonist follows a somewhat predictable step-wise structure, which La Barbera summarised as moving from experiences of 'beautified memory' to disillusionment after contact with home to an 'unfinished condition', caused by the disparity between idealisation and the experience of (physical) reality. Adhering to one of the major characteristics of the transnational migrant, the godmother, Sylvia and the other two protagonists show no indications of wanting to physically return to their home country as a place of residence; instead they appear to plant their feet firmly on two grounds simultaneously, giving up neither and engaging with both. Each protagonist finds a new place of residence in which she appears somewhere on the continuum of 'somewhat' functional to 'extremely' functional on her current landscape, in addition to engaging in arching back to the country of birth at will. Lowe Shinebourne's presentation of this reality is interesting, as it aligns with the literature on transnational experiences of being a participant in two distinct but accompanied spaces. More interestingly, in this collection is how she employs literary devices in a 'pared down' style that allows for a clearly identifiable but organic structure for tracing and immersing in the emigrant's experience. From the carefully crafted story titles to the use of three layers that construct an established and a shifted paradigm operating in the first and third layers, respectively, it is easy for the reader to become engaged and immersed in the presentations of the fluid motions between the spaces described.

Essentially, the stories are constructed with the English landscape existing in real time, with nostalgic and carefully selected memories from Guyana superimposed on it. Then, appearing on that layer of memories is a physical subject evoking the past, forcing a response from the migrant in real time. Finally, on top of these layers appears the current new reality that the migrant must live with and create in her country of residence. When these layers operate in this order, firstly, they can produce extremely positive emotions, which then give way to ambivalent feelings and finally, to a shifted perception in the migrant's experience. It also seems as if the migrant's experience or handling of the second layer determines her outlook or success in the third layer. When the paradigm shifts, it appears as if the migrant's vision can either become clear as she understands anew her purpose and finds her place in one or both landscapes, or she can struggle with reconciling the empowering memories to their jarring relationship with the landscape of residence. As a result, she might become conflicted like the godmother, or disillusioned like Sylvia, or sometimes reflective like the woman in search of red bean cakes or empowered but helpless like the sick woman in "Rebirth."

What is important to note is that the interplay between the Guyanese and foreign landscapes is unavoidable for the Guyanese emigrant, who must devise some measure of understanding and 
successfully coping with it. The handling of this interplay is, of course, dependent on the individual migrant's condition, but as seen in the stories examined, it is also dependent on the reactions of those from home who must process their own feelings about those who have migrated in addition to being aware of and often safe-guarding the feelings of their Guyanese emigrants. Developing sharper sensitivities to these migratory realities is important to countries like Guyana, which in comparison to its current population has perhaps an equally large Guyanese diaspora. Lowe Shinebourne's fiction The Godmother and Other Stories provides an opportunity to become attuned to these sensitivities, as well as to other transnational networks around the world and the currently growing research on the mechanisms involved in transnational migration.

Funding: This research received no external funding.

Conflicts of Interest: The author declares no conflict of interest.

\section{References}

Creighton, Al. 2005. The ninth awards for the Guyana Prize for Literature. Arts on Sunday. Stabroek News. April 24. Available online: http:/ / www.landofsixpeoples.com/news502/ns5042461.htm (accessed on 1 June 2018).

Danns, George K. 2018. Come-Back-Fuh-Go-Back Guyanese: The Guyanese Diaspora as Strangers. In Dynamics of Caribbean Diaspora Engagement: People, Policy, Practice. Edited by George K. Danns, Ivelaw Lloyd Griffith and Fitzgerald Yaw. Georgetown: The University of Guyana Press.

Fernandes, Andrea. 2018. More than half a million Guyanese are now living abroad. Guyana Guardian; Queens: Guardian News Syndication, February 27. Available online: https:/ /www.guyanaguardian.com/more-thanhalf-a-million-guyanese-are-living-abroad/\# (accessed on 1 June 2018).

Gill, Brenda I., Elisha J. Dung, and Paul Erhunmwunsee. 2018. Contemporary Out-Migration from CARICOM Countries: Its Impact and Potential for Growth of Diaspora Countries. In Dynamics of Caribbean Diaspora Engagement: People, Policy, Practice. Edited by George K. Danns, Ivelaw Lloyd Griffith and Fitzgerald Yaw. Georgetown: The University of Guyana Press.

Giordano, Christian. 2010. Paradigms of Migration: From Integration to Transnationalism. Culture and Society: Journal of Social Research 1: 11. Available online: http://journaldatabase.info/articles/paradigms_migration_ from_integration.html (accessed on 26 December 2018).

Glick Schiller, Nina, Linda Basch, and Cristina Szanton Blanc. 1995. From Immigrant to Transmigrant: Theorizing Transnational Migration. Anthropological Quarterly 68: 48-63. [CrossRef]

La Barbera, MariaCaterina. 2015. Chapter 1 Identity and Migration: An Introduction. In Identity and Migration in Europe: Multidisciplinary Perspectives. Edited by MariaCaterina La Barbera. Cham: Springer International Publishing, Available online: https:/ /www.researchgate.net/publication/310773419_Identity_ and_Migration_in_Europe_Multidisciplinary_Perpsectives (accessed on 26 December 2018).

Lee-Loy, Annie-Marie. 2008. A Review of Jan Lowe Shinebourne's The Godmother and Other Stories. Arts Journal: Critical Perspectives on Contemporary Literature, Art $\mathcal{E}$ Culture of Guyana $\mathcal{E}$ the Caribbean 4: 180-82.

Lowe Shinebourne, Jan. 2012. Timepiece. Leeds: Peepal Tree. First published 1986.

Lowe Shinebourne, Jan. 2013. The Godmother and Other Stories. Leeds: Peepal Tree. First published 2004.

Lowe Shinebourne, Jan. 2010. Chinese Women, A Novel. Leeds: Peepal Tree.

Lowe Shinebourne, Jan. 2015. The Last Ship. Leeds: Peepal Tree.

Melville, Pauline. 1990. Shape-Shifter. New York: Pantheon Books.

Ozkul, Derya. 2012. Transnational migration research. Sociopedia.isa. Available online: http://www.academia.edu/ 2138008/Ozkul_D._2012_._Transnational_Migration_Research_sociopedia.isa (accessed on 26 December 2018). [CrossRef]

Rahman, Karimah. 2018. Indo-Caribbean Identity Formation in Canada: Challenges of South Asian/Indian Identity. In Dynamics of Caribbean Diaspora Engagement: People, Policy, Practice. Edited by George K. Danns, Ivelaw Lloyd Griffith and Fitzgerald Yaw. Georgetown: The University of Guyana Press.

Ramdeholl, Dianne. 2018. Home and Diaspora: Unpacking Understandings of Home, Place/Space, and Belongings in a Postcolonial Context. In Dynamics of Caribbean Diaspora Engagement: People, Policy, Practice. Edited by George K. Danns, Ivelaw Lloyd Griffith and Fitzgerald Yaw. Georgetown: The University of Guyana Press. 
Smith, Aieka Yasheva. 2018. Physically Separate but Psychologically Inseparable: Notions of Belonging and Identity Among Jamaicans Living in Britain. In Dynamics of Caribbean Diaspora Engagement: People, Policy, Practice. Edited by George K. Danns, Ivelaw Lloyd Griffith and Fitzgerald Yaw. Georgetown: The University of Guyana Press.

World Bank Group. 2016. Migration and Remittances Factbook 2016, 3rd ed. Washington, DC: World Bank.

World Population Review. 2018. Guyana Population 2018. June 16. Available online: http:/ / worldpopulationreview. com/countries/guyana-population/ (accessed on 16 June 2018). 